\title{
Research on Applying Teaching Games for Understanding Approach to the Training of University Women's Basketball Team-A Case Study of Women's Basketball Team of Xi'an University of Technology
}

\author{
Nan Zhang ${ }^{1, *}$, Manhua $\mathrm{Li}^{1}$ \\ ${ }^{1}$ Sport Institute, Xi'an University of Technology, Xi'an710048, China \\ "Corresponding author. Email: bluenan1@126.com
}

\begin{abstract}
By literature and case study, this paper analyzes the results of application of teaching games for understanding approach to the training to solve the problem of players' low level, tight schedule and inexperience. The results of the research are as follows: the training efficiency techniques and tactics are improved; players learn about the basketball rules thoroughly; players can control the rhythm of the game better; the ability to analyze and solve the problem is developed; self-confidence is enhanced.

Keywords: university, training of women's basketball team, teaching games for understanding approach
\end{abstract}

\section{新时期高校女篮训练运用 “领会教学法” 的探索研究 以西安理工大学女篮为例 \\ 张楠 ${ }^{1},{ }^{*}{ }^{*}$,李曼华 ${ }^{1}$}

1 西安理工大学体育部, 西安, 陕西, 中国

abluenan1@126.com

“通讯作者

中文摘要.

采用文献法、实验法, 针对高校普通组女篮队员运动水平较低、训练时间短、比赛经验少等特点, 运 用 “领会教学法” 到高校女篮训练中, 实践证明在较短的训练周期内能帮助队员提高训练效率, 快速 提升技战术水平, 全面了解篮球规则和裁判法相关知识, 掌控比赛节奏以及更好更快的培养了队员分 析问题、解决问题的能力，自信心也得到了提高。

关键词: 高校; 女篮训练; 领会教学法

\section{1.引言}

第22届中国大学生篮球联赛陕西赛区的比赛 2019 年11月在西安拉开帷幕, 陕西省共有 65 所学校的111支 队伍近 2000 名运动员、教练员参赛, 人数为历年之最 西安理工大学在多年未参加女篮赛事的情况下临时 组队参赛, 由于时间紧迫, 笔者根据队伍实际情况, 运用 “领会教学法” 对女子篮球队进行了为期一个半 月的训练, 效果显著。队伍在二级联赛小组赛中三克 强敌顺利杀入淘汰赛, 取得了不错的战绩。球队不仅
出色的完成了组队时的任务, 而且为 “领会教学法” 在运动队训练中的应用积累了宝贵的实践经验。

\section{2. “领会教学法” 的概念以及特征}

“领会教学法” 是英国体育学者邦克和桑普 (Bunker\&Thorpe)于 80 年代初提出的革新球类教学的一 种思路, 其基本指导思想是把球类运动的特点及战术 意识，而不是技巧动作本身作为球类教学的重点。在 教学中把教授学生领会篮球运动的特性与战术作为篮 
几乎没有, 所以一打正规比赛就表现的非常紧张, 练 的东西打不出来, 没有自信, 好在现在的女孩子都有 一颗大心脏, 一旦失败输掉比赛会很快恢复元气投入 到下场比赛中, 有不服输的精神。

\section{4.运用 “领会教学法” 训练高校女子篮球运 动员的优势}

\section{1. “领会教学法” 更容易使高校女子运动 员建立起篮球比赛的整体概念}

要在短时间内建立起篮球比赛的整体概念是非常 困难的，尤其是在队员个人技术水平较差的前提下， 强调队伍整体作战, 多使用成熟的战术可能是取得胜 利的唯一出路。“领会教学法” 对队员篮球战术意识 的培养, 位置的移动及动作的目的性更为明确, 更能 让队员明白自己的职责, 以及通过比赛明白自己位置 上所需要的个人基本技术。领会教学法要求队员在不 同的战术位置上进行更多的思考, 提高她们的创造 力, 提升比赛中的行动力。运用领会教学法, 侧重的 是整体篮球战术的领会, 注重队员之间的相互配合, 在篮球训练的各个环节中体现战术, 反复强化学生的 战术意识。根据我校女队员的身体特点, 我们专门设 计了边线球战术、底线球战术以及防守战术等适合她 们的战术打法, 在反复的练习配合中, 不断强化, 队 员更容易体会到集体的重要性。同时, 篮球比赛的一 个重要部分就是篮球规则和裁判法。利用领会教学法 进行篮球训练使用了大量的篮球游戏以及正规的比赛 形式, 使队员能够了解、熟知篮球的规则以及裁判的 判罚尺度, 随后在激烈的比赛中能逐渐把握好身体接 触的尺度, 有理有据的与裁判员讨论场上的问题, 巧 妙利用规则赢得比赛的最后胜利。

\section{2. “领会教学法” 对高校女篮运动员的 基本技能的提高更具有针对性}

当前高校普通组女篮的训练, 由于训练时间有 限, 还要有成绩上的要求就必须找到一个有别于传统 的、更高效的训练方法。“领会教学法” 多以教学比 赛作为主要内容, 在比赛中提高队员个体的基本技术 以及合理运用技术的能力。这样队员在练习基本技能 时, 就明白了为什么要练这个技术, 学习的目标就很 清晰, 学习动机也就比较明确[3]。运用领会教学法后 队员对篮球基本技术的实战运用能力也得到大幅提 升。如在教学比赛中队员控球的能力明显提升, 由原 来的害怕防守变成敢于运球敢于突破, 能有目的有意 识地选择合理的技术动作进行对抗。在实际训练中为 了较快的形成战斗力, 我们针对前锋、中锋和后位所 要掌握的基本技术进行了分类，找出一些适合位置、 适合队员的关键技术动作有针对性地强化练习、反复 
以队员整体性认知能力的提高为教学训练的目标。运 用 “领会教学法” 训练的整个过程都以教学比赛为主 线, 实际上遵循的是队员篮球运动能力的一次次磨 练, 训练效率高, 训练效果好。

\section{REFERENCES}

[1] Zhang Nan. Experimental Study on Applying Teaching Games for Understanding Approach to the Teaching of Basketball Specialized Course in Colleges. Journal of Xi'an Institute of Physical Education, vol.20, pp. 90-93, 2003.

[2] Li jie.The research on the connotation and characteristics of teaching games for understanding. Journal of Sports and Science, vol. 38, pp. 42-48, 2017.

[3] Wegner D. M., Erber, R., \& Zanakos, S. Ironic processes in the mental control of mood-related thought. Journal of Personality and Social Psychology, vol. 65, pp. 1093-1104, 1993.

[4]Schumann P L. A moral principles framework for human resource management ethics [J].Human Resource Management Review, vol.11, pp.93-111, 2001.

[5] Judith E., Karen E, \&Bonnie L. Foundations for the Learning and Instruction of Sport and Games [J]. Journal of Teaching in Physical Education, vol.15, pp. 399-417, 1996.

[6] Zhang yan. Competition Training Method in University Basketball Tactic Teaching [J]. Journal of Luoyang Normal University, vol. 28, pp. 97-101, 2009.

[7] Bunker D, Thorpe R. Model for the Teaching of Games in Secondary [J]. Bulletin of PE, 1982,18(1):5-8.

[8] Fort R, Lee Y H, Berri D. Race. Technical Efficiency and Retention: The Case of NBA Coaches [J]. International Journal of Sport Finance, vol. 3, pp. 84-97, 2008.

\section{6.结论}

“领会教学法” 非常适合训练高校普通组的女子 篮球运动员, 她从实际出发, 以队员已有的篮球运动 能力水平为基础, 充分发挥队员的积极性和主动性, 